\title{
FAKTOR-FAKTOR YANG DIPERTIMBANGKAN INVESTOR DALAM MELAKUKAN INVESTASI
}

\author{
Natalia Christanti (ze2c_nath_shagygirl@yahoo.co.id) \\ Linda Ariany Mahastanti (Linda.ariany@staff.uksw.edu) \\ Fakultas Ekonomika dan Bisnis Unversitas Kristen Satya Wacana, Salatiga
}

\begin{abstract}
Investor has many options in an investment with the current number of investment instruments. Previous studies of retail investor behavior have examined motivation from economic perspectives or studied relationships between economic, behavioral and demographic variables. Examination of the various utility-maximization and behavioral variables underlying individual investor behavior provides a more comprehensive understanding of the investment decision process. This research will examine the seven factors that considered investors' decisions to invest, and investor behavior in taking the decision to invest. The data used are primary data that obtained by sending questionnaires through via email at Danareksa investors domiciled in Salatiga and Semarang. The analysis method used is tabulation frequencies and cross tabulation (Crosstab). Based on the results of the research, it is known that the factors that considered investor' decisions is Neutral Information and Accounting Information factor. For the result of demographic aspects effect research against investment decision is investor who are aged 25-29 and 50-54 years which is considered all of the factors. While for sex, female consider many factors than male. For educational level with high educational level makes the investor pay attention to the factors that associated with investment decisions, and investors who invest for 1-3 years old considering many factors before making investment decisions.
\end{abstract}

Keywords: Investment, Investor Behavior, Considering Factor

\section{PENDAHULUAN}

Pasar modal Indonesia yang sekarang ini sedang membaik pasca krisis, yang dapat dilihat dari pertumbuhan ekonomi Indonesia yang bertumbuh pada level 4,5\%-5,5\% dan diperkirakan akan meningkat untuk tahun-tahun berikutnya. Selain itu dengan naiknya indeks BEI (Bursa Efek Indonesia) dan Pasar modal Indonesia dilihat dari IHSG penutupan tahun 2007 sebesar 52,1\%, 2008 sebesar 51,17\%, dan 2009 sebesar 68,06\%, sehingga Indonesia dinilai akan menjadi salah satu pilihan investasi utama dunia pada tahun 2010 sehingga dana-dana invetasi asing akan mengalir di Indonesia.

Dengan adanya perkembangan investasi, perilaku keuangan sangat berperan dalam pengambilan keputusan seseorang untuk berinvestasi. Pengambilan keputusan keuangan untuk kegiatan investasi, akan sangat dipengaruhi oleh informasi yang didapat dan pengetahuan investor tentang investasi. Keputusan investasi seorang investor selama ini dilihat dari dua sisi yaitu, (1) sejauh mana keputusan dapat memaksimalkan kekayaan (economic) (2) behavioral motivation (keputusan investasi berdasarkan aspek psikologis investor).

Biasanya seorang investor akan melakukan riset sebelum memutuskan untuk melakukan investasi, seperti dengan mempelajari laporan keuangan perusahaan, kinerja perusahaan, track record atau portofolio, keadaan perekonomian, risiko, ulasan tentang keuangan dan keadaan perekonomian yang dipublikasikan di media, dan lain-lain riset ini dilakukan dengan tujuan supaya investasi yang dilakukan dapat memberikan tambahan kekayaan. Berdasarkan utility theory yang dikembangkan oleh Von Neumann dan Morgenstern, mengatakan bahwa (1) investor sangat rasional, (2) setuju dengan pilihan yang kompleks, 
(3) tidak suka risiko dan, (4) memaksimalkan kekayaan. Dengan adanya perkembangan dari masa ke masa, maka muncullah teori lain yang dapat mempengaruhi keputusan investasi investor berdasarkan aspek psikologis (behavioral motivation). Selain itu berdasarkan studi empiris tentang perilaku investor yang dilakukan oleh Blume akk pada tahun 1970, menguji bagaimana variabel demografi mempengaruhi proses pemilihan dan komposisi portofolio investasi.

Faktor lain yang dapat mempengaruhi keputusan investasi investor yaitu behavioral motivation yang dapat dilihat dari variabel demografi, seperti jenis kelamin, usia dan pendidikan. Lewellen, Lease dan Schlarbaum (1977) menetapkan bahwa usia, jenis kelamin, pendapatan dan pendidikan mempengaruhi pilihan investor untuk keuntungan, dividen dan semua laba yang diinginkan. Selain itu (Warren akk, 1990) menyatakan bahwa.pilihan investasi seseorang lebih berdasar pada gaya hidup dan karakteristik demografinya.

Kebanyakan investor dalam keputusan berinvestasi hanya melihat dan mempertimbangkan faktor Accounting Information agar tujuan investasinya tercapai, namun faktor-faktor yang lain tidak banyak diperhatikan. Faktor tersebut biasa disebut sebagai alat analisis tradisional dan investor biasanya sudah merasa cukup dengan melihat kedua faktor tersebut untuk menentukan keputusan investasi, selain itu memang banyak investor yang tidak mengetahui bahwa ada faktor lain yang dapat dijadikan pertimbangan sebelum melakukan investasi.

Nagy dan Obenberger (1994) dalam penelitiannya mengklasifikasikan beberapa faktor lain selain Accounting Information dan Self Image/Firm-Image Coincidence yang juga mempengaruhi seorang investor dalam melakukan investasi yaitu faktor Neutral Information, Classic, Social Relevance, Advocate Recommendation, dan Personal Financial Needs. Dalam penelitian yang dilakukan oleh Nagy dan Obenberger menyatakan bahwa investor sekarang berbeda, tidak lagi hanya melihat faktor-faktor yang sudah biasa saja namun juga memperhitungkan faktor-faktor lain sebelum melakukan investasi, dan faktor yang paling diperhitungkan oleh investor pada penelitian Nagy dan Obenberger adalah estimasi keuntungan perusahaan di masa datang yang merupakan variabel economic untuk memaksimalkan kekayaan.

Al-Tamimi (2004) melakukan penelitian terhadap investor di Dubai (UAE) menyatakan bahwa estimasi laba perusahaan adalah faktor yang paling berpengaruh dalam pengambilan keputusan, sedangkan faktor religius tidak memberikan pengaruh terhadap pengambilan keputusan investasi.

Fokus dalam penelitian ini adalah meneliti faktor-faktor yang dipertimbangkan investor dalam melakukan keputusan investasi dengan menggunakan klasifikasi faktor dari (Nagy dan Obenberger ,1994)) dimana klasifikasi faktor ini dibagi dalam dua sudut pandang economic dan behavioral motivation

\section{TELAAH TEORITIS}

Investasi pada hakikatnya merupakan penempatan sejumlah dana pada saat ini dengan harapan dapat menghasilkan keuntungan di masa depan (Halim, 2005). Sehingga dalam melakukan keputusan investasi, investor memerlukan informasi-informasi yang merupakan faktor-faktor penting sebagai dasar untuk menentukan pilihan investasi. Dari informasi yang ada, kemudian membentuk suatu model pengambilan keputusan yang berupa kriteria penilaian investasi untuk memungkinkan investor memilih investasi terbaik di antara alternatif investasi yang tersedia.

Utility Theory adalah teori yang digunakan untuk menjelaskan sikap seseorang terhadap risiko. Dimana dalam penelitian ini sikap investor dalam melakukan investasi untuk menghindari risiko agar dapat memaksimalkan kekayaan (Economic Factor). Berdasarkan 
klasifikasi faktor Nagy dan Obenberger, Economic Factor meliputi Neutral Information, Accounting Information, Classic.

Behavioral motivation yaitu keputusan investasi berdasarkan psikologi investor atau sesuatu yang diyakininya, yang meliputi faktor Self Image/Firm-Image Coincidence, Social Relevance, Advocate Recommendation, Personal Financial Needs.

Neutral Information dimana informasi berasal dari luar yang menunjukkan gambaran agar informasi-informasi yang didapat tidak berat sebelah, informasi ini mencangkup ulasan dan informasi dari media tentang keuangan maupun keadaan ekonomi yang berhubungan dengan kegiatan investasi yang meliputi informasi tentang pemberitaan atau ulasan di media keuangan yang biasanya membahas tetang keadaan atau kondisi saat ini dengan perkembangan investasi yang ada serta hal-hal lain yang berhubungan dengan investasi dan keuangan, pemberitaan atau ulasan di media umum, perubahan harga saham, ulasan dari analis keuangan yang dipublikasikan di media, dan indikator ekonomi (inflasi, tingkat suku bunga, dan lain-lain) (Nagy dan Obenberger, 1994).

Accounting Information yaitu informasi yang berhubungan dengan laporan keuangan perusahaan, meliputi data pada laporan dan prospectus, penilaian terhadap saham dengan menghitung NPV, IRR, dan lain-lain, pendapatan atau laba perusahaan yang diharapkan, sejarah pendirian perusahaan, dan kemampuan bursa saham saat ini (Nagy dan Obenberger, 1994).

Self Image/Firm-Image Coincidence merupakan informasi yang berhubungan dengan penilaian terhadap perusahaan, meliputi informasi tentang reputasi perusahaan, posisi perusahaan pada industri yaitu termasuk market leader atau market follower, new comers, perkiraan produk dan pelayanan perusahaan, mengetahui etika-etika perusahaan, nilai saham perusahaan pada waktu yang lalu (Nagy dan Obenberger, 1994).

Classic merupakan kemampuan investor menentukan kriteria pada dasar ekonomis dari perilaku investor, meliputi informasi tentang dividen yang diharapkan, harga saham pada pembukaan, konsekuensi pajak yang harus ditanggung, dan kemampuan untuk memperkecil risiko (Nagy dan Obenberger, 1994).

Social Relevance menyangkut informasi keberadaan saham perusahaan di bursa saham dan tanggung jawab sosial perusahaan, yang meliputi informasi tentang posisi saham dalam saham-saham yang terdaftar pada bursa saham termasuk saham blue chip atau second liner, jenis investasi yang beroperasi di area lokal, jenis investasi yang beroperasi di area internasional, dan bentuk kepedulian perusahaan terhadap lingkungan (Corporate Social Responsibility) (Nagy dan Obenberger, 1994).

Advocate Recommendation dimana sumber informasi dapat membangun gagasan dan pemahaman berdasarkan rekomendasi yang telah diberikan dengan memperhatikan kepentingan tetap dalam hasil pada kegiatan pokok investor, hal ini juga diungkapkan oleh Toral (2002) bahwa investor dalam pemilihan investasi membutuhkan tenaga profesional sehingga tidak ada kecemasan dalam memilih investasi di saat keadaan pasar sedang lesu, informasi tersebut meliputi rekomendasi dari broker, rekomendasi dari teman, dan pendapat dari keluarga (Nagy dan Obenberger, 1994).

Personal Financial Needs jenis informasi ini didapat berdasarkan pengalaman investor dalam melihat nilai investasi dan perhitungan pada pengeluaran konsumsi sebagai seorang yang sungguh indipenden, yang meliputi informasi tentang target hasil dari investasi untuk memenuhi keuangan pribadi, estimasi dana untuk investasi, keinginan diversifikasi, melihat kembali kinerja portofolio saham yang dimiliki di masa yang lalu, melihat alternatif investasi lain selain yang telah dimiliki dengan melakukan perbandingan alternatif investasi selain saham, misalnya obligasi, emas, deposito, dan lain-lain (Nagy dan Obenberger, 1994) . 
Berdasarkan teori portofolio, bahwa para investor di bursa melakukan diversifikasi/membentuk portofolio karena ingin mengurangi risiko. Namun ada juga risiko yang sifatnya sistematis dimana risiko ini sangat dipengaruhi oleh kondisi perekonomian yaitu pada saat perekonomian membaik akan membawa dampak positif bagi perusahaanperusahaan, dan sebaliknya apabila perekonomian memburuk akan berdampak negatif bagi perusahaan-perusahaan. Kondisi perekonomian (faktor ekonomi makro) sangat mempengaruhi jenis-jenis industri tertentu dan hal ini merupakan risiko sistematis, sehingga intensitas dampak perekonomian akan terasa pada perusahaan yang sensitif terhadap keadaan perekonomian.

Hasil penelitian yang dilakukan Alok (2009), menunujukkan bahwa seorang investor lebih memperhatikan komposisi portofolio karena hal ini mempengaruhi pendapatan dalam jangka panjang, hasil/laba yang didapat dari portofolio sebelumnya, nasihat/berita yang dimuat di media cetak yang berhubungan dengan investasi, dan yang paling penting adalah mempertimbangkan keadaan makro ekonomi dan variabel yang digunakan dalam memperkirakan aliran dana di masa yang akan datang.

Suatu investasi dapat dikatakan menguntungkan (profitable) jika investasi tersebut dapat menjadikan investor lebih kaya atau tingkat kemakmuran investor menjadi lebih baik setelah melakukan investasi. Melihat atau menghitung NPV penting karena menunjukkan tambahan kemakmuran investor, perkiraan arus kas atas dasar setelah pajak karena penghasilan pemilik perusahaan adalah kas masuk bersih setelah pajak. Untuk penilaian terhadap saham dengan menggunakan NPV atau IRR sangat dipengaruhi oleh penentuan atau penggunaan indikator ekonomi seperti tingkat suku bunga, inflasi yang dapat berdampak pada arus kas dan tingkat keuntungan.

\section{METODE PENELITIAN}

Data yang dikumpulkan berasal dari data primer dengan menyebar kuesioner sebanyak 300 melalui email kepada investor yang tergabung dengan sekuritas Danareksa yang berdomisili di Salatiga dan Semarang. Sampel pada penelitian ini sebanyak 69 responden atau $23 \%$ dari total keseluruhan.

Untuk memperoleh informasi data-data yang digunakan dalam penelitian ini digunakan kuesioner, yang didalamnya terdapat 33 pertanyaan yang harus dijawab oleh responden. Dimana 33 pertanyaan merupakan tujuh faktor yang dipertimbangkan investor dalam keputusan investasinya dan untuk setiap faktor memiliki beberapa indikator yaitu faktor Neutral Information dan Accounting Information masing-masing memiliki 6 indikator, Self Image/Firm-Image Coincidence memiliki 5 indikator, Classic dan Social Relevance ada 4 indikator, Advocate Recommendation terdapat 3 indikator, Personal Financial Need memiliki 5 indikator. Terdapat tiga pengelompokan jawaban untuk masing-masing variabel yaitu; (1) Sangat dipertimbangkan dalam keputusan investasi atau berpengaruh dalam keputusan investasi, (2) Kadang-kadang dipertimbangkan atau kadang berpengaruh kadang tidak, (3) Sama sekali tidak dipertimbangkan atau tidak mempengaruhi keputusan investasi, selanjutnya dari jawaban tersebut varibel-variabel akan di rangking. Dari hasil tersebut akan dianalisis dan menjelaskan arti dari angka-angka yang tercantum secara deskriptif.

Metode penelitian yang digunakan adalah metode deskriptif frekuensi dan tabel silang (Crosstab), analisis crosstab bertujuan untuk mengetahui ada atau tidaknya hubungan antara karakteristik investor terhadap keputusan investasi. Sedangkan analisis frekuensi dilakukan untuk mengetahui seberapa sering jawaban kelompok responden untuk setiap variabel.

Jenis data dalam penelitian ini adalah data kualitatif yaitu data yang tidak bisa dihitung dalam angka, tetapi dapat diukur atau dikategorikan dalam berbagai golongan. Maka pengolahan data menggunakan analisis deskriptif dengan SPSS (Statistical Program for 
Social Science version 11 for Windows). Sedangkan analisis tabulasi silang (crosstab) dilakukan untuk menguji variabel demografi atau karakteristik investor (usia, jenis kelamin, tingkat pendidikan, lama investasi) dengan jawaban dari 33 variabel yang merupakan itemitem dari faktor Neutral Information, Accounting Information, Self Image/Firm-Image Coincidence, Classic, Social Relevance, Advocate Recommendation, Personal Financial Need, yang merupakan faktor yang dipertimbangkan dalam keputusan investasi.

\section{HASIL ANALISIS}

Karakteristik Responden

Setelah data terkumpul ternyata kuesioner yang kembali sebanyak 69 atau $23 \%$ dari keseluruhan kuesioner. Kemudian data diolah dengan menggunakan SPSS untuk analisis frekuensi dan tabulasi silang (croostab), dan hasilnya sebagai berikut:

Tabel 1. Frekuensi Jenis Kelamin Responden

\begin{tabular}{|ll|r|r|r|r|}
\hline & & & & \multicolumn{1}{c|}{$\begin{array}{c}\text { Cumulative } \\
\text { Percent }\end{array}$} \\
\hline Valid & PEREMPUAN & 10 & 14.5 & 14.5 & 14.5 \\
& LAKI-LAKI & 59 & 85.5 & 85.5 & 100.0 \\
& Total & 69 & 100.0 & 100.0 & \\
\hline
\end{tabular}

Sumber: Data Olahan

Berdasarkan analisis menggunakan metode deskriptif frekuensi, dari 69 responden untuk frekuensi jenis kelamin di dapat hasil bahwa pada penelitian ini jumlah responden berjenis kelamin laki-laki lebih banyak di bandingkan dengan responden perempuan. Hal ini dapat terjadi karena masih belum banyak perempuan yang mau atau berani berinvestasi di pasar modal, sebab perempuan lebih takut akan risiko dibandingkan dengan laki-laki. Seperti pendapat Khan (dalam Hasanat, 1994 dan dalam Khairani \& Putri, 2009) yang menyatakan bahwa wanita memiliki kehangatan emosionalitas, sikap hati-hati dan sensitif dari pada pria. Sedangkan untuk tingkat emosional, wanita lebih emosional sehingga tingkat kematangan emosinya rendah dibandingkan dengan pria yang lebih rasional dan menggunakan logika sehingga tingkat kematangan emosinya lebih tinggi (Shields dalam Santrock, 2003 dan dalam Khairani \& Putri, 2009). Dilihat dari tujuan atau kepentingan investasi antara laki-laki dan perempuan juga berbeda, laki-laki bertujuan untuk kepentingan mencari nafkah sedangkan perempuan untuk pemenuhan emosinya guna memberikan perhatian pada keluarga.

Tabel 2. Frekuensi Usia Responden

\begin{tabular}{|c|c|c|c|c|c|}
\hline & & Frequency & Percent & Valid Percent & $\begin{array}{c}\text { Cumulative } \\
\text { Percent }\end{array}$ \\
\hline \multirow[t]{8}{*}{ Valid } & $20-24$ & 17 & 24.6 & 24.6 & 24.6 \\
\hline & $25-29$ & 21 & 30.4 & 30.4 & 55.1 \\
\hline & 30-34 & 12 & 17.4 & 17.4 & 72.5 \\
\hline & $35-39$ & 9 & 13.0 & 13.0 & 85.5 \\
\hline & $40-44$ & 3 & 4.3 & 4.3 & 89.9 \\
\hline & $45-49$ & 5 & 7.2 & 7.2 & 97.1 \\
\hline & $50-54$ & 2 & 2.9 & 2.9 & 100.0 \\
\hline & Total & 69 & 100.0 & 100.0 & \\
\hline
\end{tabular}

Sumber: Data Olahan

Untuk analisis frekuensi berdasarkan usia terlihat pada Tabel 2. yaitu responden rata-rata berusia 25-29 tahun, dimana pada usia ini investor berada pada usia produktif dan fase pengembangan karir dan urusan keluarga sehingga seluruh kemampuannya digunakan 
untuk bekerja dan menghasilkan uang sebanyak mungkin untuk digunakan pada hari tua mereka.

Tabel 3. Frekuensi Tingkat Pendidikan Responden

\begin{tabular}{|ll|r|r|r|r|}
\hline & & & & Cumulative \\
& & Frequency & Percent & Valid Percent & Percent \\
\hline Valid & SMA & 2 & 2.9 & 2.9 & 2.9 \\
& S1 & 63 & 91.3 & 91.3 & 94.2 \\
& S2 & 4 & 5.8 & 5.8 & 100.0 \\
& Total & 69 & 100.0 & 100.0 & \\
\hline
\end{tabular}

Sumber: Data Olahan

Berdasarkan analisis frekuensi berdasarkan tingkat pendidikan, didominasi oleh responden dengan tingkat pendidikan lulusan S1 yang merupakan tingkat pendidikan yang cukup tinggi. Pada tingkat pendidikan ini dapat digolongkan pada usia $>25$ tahun, yaitu investor sudah memiliki pengetahuan dan pemikiran yang lebih baik, dimana untuk menganalisis dan mengambil keputusan investasi sudah bagus.

Tabel 4. Frekuensi Lama Investasi Responden

\begin{tabular}{|c|c|c|c|c|c|}
\hline & & Frequency & Percent & Valid Percent & $\begin{array}{c}\text { Cumulative } \\
\text { Percent }\end{array}$ \\
\hline \multirow[t]{5}{*}{ Valid } & $<1$ Tahun & 1 & 1.4 & 1.4 & 1.4 \\
\hline & 1-3 Tahun & 46 & 66.7 & 66.7 & 68.1 \\
\hline & 4-6 Tahun & 13 & 18.8 & 18.8 & 87.0 \\
\hline & $>6$ Tahun & 9 & 13.0 & 13.0 & 100.0 \\
\hline & Total & 69 & 100.0 & 100.0 & \\
\hline
\end{tabular}

Sumber: Data Olahan

Frekuensi paling banyak untuk lama investasi responden ada pada 1-3 tahun, dimana responden masih berada pada tahap awal pengenalan dan pengembangan investasi. Hal ini disebabkan karena baru lima tahun terakhir pasar modal di Indonesia diminati oleh investor dengan semakin meningkatnya IHSG dari tahun-ke tahun.

Pada Tabel 5. Dan Tabel 6. berikut ini menunjukkan hasil rangking dari setiap indikatorindikator yang digunakan untuk mengukur faktor Neutral Information, Accounting Information, Self Image/Firm-Image Coincidence, Classic, Social Relevance, Advocate Recommendation, Personal Financial Need berdasarkan hasil jawaban kriteria yang sangat dipertimbangkan dan yang tidak dipertimbangkan dalam keputusan investasi investor.

Tabel 5. Frekuensi Variabel yang Sangat dipertimbangkan dalam Keputusan Investasi

\begin{tabular}{|c|c|c|c|c|}
\hline Kategori & Rank & Variabel & Jumlah & Prosentase \\
\hline $\mathrm{Ne}$ & 1 & Pemberitaan/ulasan di media keuangan & 69 & $100 \%$ \\
\hline $\mathrm{Ne}$ & 2 & Kondisi perekonomian saat ini secara umum & 69 & $100 \%$ \\
\hline $\mathrm{Ne}$ & 3 & $\begin{array}{l}\text { Perubahan harga dari saham perusahaan baru- } \\
\text { baru ini }\end{array}$ & 68 & $99 \%$ \\
\hline $\mathrm{Ne}$ & 4 & Pemberitaan/ulasan di media umum & 67 & $97 \%$ \\
\hline $\mathrm{Ne}$ & 5 & $\begin{array}{l}\text { Memperhatikan indikator ekonomi } \\
\text { tingkat suku bunga,dll) }\end{array}$ & 67 & $97 \%$ \\
\hline Ac & 6 & Laporan keuangan perusahaan saat ini & 67 & $97 \%$ \\
\hline $\mathrm{Ne}$ & 7 & Ulasan dari analis keuangan yang dipublikasikan & 66 & $96 \%$ \\
\hline
\end{tabular}




\begin{tabular}{|c|c|c|c|c|}
\hline & & di media & & \\
\hline $\mathrm{Cl}$ & 8 & Harga saham pembukaan & 66 & $96 \%$ \\
\hline$A c$ & 9 & Pendapatan perusahaan yang diharapkan & 61 & $88 \%$ \\
\hline $\mathrm{Se}$ & 10 & Reputasi perusahaan & 61 & $88 \%$ \\
\hline $\mathrm{Pe}$ & 11 & $\begin{array}{l}\text { Kinerja portofolio saham yang dimiliki di masa } \\
\text { yang lalu }\end{array}$ & 61 & $88 \%$ \\
\hline$A c$ & 12 & Kemampuan bursa saham saat ini & 60 & $87 \%$ \\
\hline $\mathrm{Se}$ & 13 & Nilai saham perusahaan sebelumnya & 60 & $87 \%$ \\
\hline $\mathrm{Cl}$ & 14 & Memperkecil risiko & 57 & $83 \%$ \\
\hline $\mathrm{Pe}$ & 15 & Estimasi dana untuk investasi & 57 & $83 \%$ \\
\hline $\mathrm{Ac}$ & 16 & Data pada laporan dan prospectus & 56 & $81 \%$ \\
\hline $\mathrm{Pe}$ & 17 & Keinginan diversifikasi & 56 & $81 \%$ \\
\hline $\mathrm{Pe}$ & 18 & $\begin{array}{l}\text { Target hasil investasi yang dinginkan untuk } \\
\text { memuhi kebutuhan keuangan pribadi }\end{array}$ & 55 & $80 \%$ \\
\hline$A c$ & 19 & Penilaian terhadap saham (NPV, IRR, dIII) & 51 & $74 \%$ \\
\hline $\mathrm{Se}$ & 20 & $\begin{array}{l}\text { Posisi perusahaan pada industri (market leader, } \\
\text { market follower, new comers,dll) }\end{array}$ & 51 & $74 \%$ \\
\hline $\mathrm{Cl}$ & 21 & Dividen yang diharapkan & 51 & $74 \%$ \\
\hline So & 22 & $\begin{array}{l}\text { Posisi saham pada daftar bursa saham (blue } \\
\text { chip, second liner) }\end{array}$ & 50 & $72 \%$ \\
\hline $\mathrm{Pe}$ & 23 & $\begin{array}{l}\text { Melakukan perbandingan alternatif investasi lain } \\
\text { (obligasi, emas, deposito,dll) }\end{array}$ & 50 & $72 \%$ \\
\hline Ac & 24 & Pendirian perusahaan & 49 & $71 \%$ \\
\hline So & 25 & $\begin{array}{lll}\begin{array}{l}\text { Bentuk kepedulian } \\
\text { lingkungan (CSR) }\end{array} & \text { perusahaan terhadap } \\
\end{array}$ & 44 & $64 \%$ \\
\hline Ad & 26 & Rekomendasi saham dari broker & 44 & $64 \%$ \\
\hline $\mathrm{Cl}$ & 27 & Konsekuensi pajak & 43 & $62 \%$ \\
\hline $\mathrm{Se}$ & 28 & $\begin{array}{l}\text { Perkiraan pada produk dan pelayanan } \\
\text { perusahaan }\end{array}$ & 42 & $61 \%$ \\
\hline $\mathrm{Se}$ & 29 & Mengetahui etika-etika dari perusahaan & 42 & $61 \%$ \\
\hline So & 30 & $\begin{array}{l}\text { Saya lebih memilih jenis investasi yang } \\
\text { beroperasi di lokal }\end{array}$ & 42 & $61 \%$ \\
\hline Ad & 31 & Rekomendasi dari teman atau teman kerja & 42 & $61 \%$ \\
\hline So & 32 & $\begin{array}{l}\text { Saya lebih memilih jenis investasi yang } \\
\text { beroperasi di internasional }\end{array}$ & 39 & $57 \%$ \\
\hline Ad & 33 & Pendapat keluarga & 38 & $55 \%$ \\
\hline
\end{tabular}

Sumber: Data Olahan

Tabel 6. Frekuensi Variabel yang Tidak dipertimbangkan dalam Keputusan Investasi

\begin{tabular}{|c|c|l|c|c|}
\hline Kategori & Rank & \multicolumn{1}{|c|}{ Variabel } & Jumlah & Prosentase \\
\hline Se & 1 & Mengetahui etika-etika dari perusahaan & 12 & $17 \%$ \\
\hline Cl & 2 & Konsekuensi pajak & 11 & $16 \%$ \\
\hline So & 3 & $\begin{array}{l}\text { Saya lebih memilih jenis investasi yang beroperasi } \\
\text { di internasional }\end{array}$ & 10 & $14 \%$ \\
\hline Ad & 4 & Pendapat keluarga & 10 & $14 \%$ \\
\hline Se & 5 & Perkiraan pada produk \& pelayanan perusahaan & 9 & $13 \%$ \\
\hline So & 6 & $\begin{array}{l}\text { Saya lebih memilih jenis investasi yang beroperasi } \\
\text { di lokal }\end{array}$ & 9 & $13 \%$ \\
\hline
\end{tabular}




\begin{tabular}{|c|c|c|c|c|}
\hline So & 7 & $\begin{array}{l}\text { Bentuk kepedulian perusahaan terhadap } \\
\text { lingkungan (Corporate Social Responsibility) }\end{array}$ & 8 & $12 \%$ \\
\hline Ac & 8 & Pendirian perusahaan & 5 & $7 \%$ \\
\hline Ac & 9 & Penilaian terhadap saham (NPV, IRR,dll) & 4 & $6 \%$ \\
\hline $\mathrm{Cl}$ & 10 & Memperkecil risiko & 4 & $6 \%$ \\
\hline So & 11 & $\begin{array}{l}\text { Posisi saham dalam saham yang terdaftar pada } \\
\text { bursa saham (blue chip, second liner) }\end{array}$ & 4 & $6 \%$ \\
\hline Ad & 12 & Rekomendasi saham dari broker & 4 & $6 \%$ \\
\hline Ad & 13 & Rekomendasi dari teman atau teman kerja & 3 & $4 \%$ \\
\hline$A c$ & 14 & Pendapatan perusahaan yang diharapkan & 2 & $3 \%$ \\
\hline $\mathrm{Se}$ & 15 & $\begin{array}{l}\text { Posisi perusahaan pada industri (market leader, } \\
\text { market follower, new comers,dll) }\end{array}$ & 2 & $3 \%$ \\
\hline $\mathrm{Pe}$ & 16 & $\begin{array}{l}\text { Target hasil investasi yang dinginkan untuk } \\
\text { memuhi kebutuhan keuangan pribadi }\end{array}$ & 2 & $3 \%$ \\
\hline $\mathrm{Pe}$ & 17 & Estimasi dana untuk investasi & 2 & $3 \%$ \\
\hline $\mathrm{Pe}$ & 18 & Keinginan diversifikasi & 2 & $3 \%$ \\
\hline Ac & 19 & Data pada laporan dan prospectus & 1 & $1 \%$ \\
\hline $\mathrm{Cl}$ & 20 & Dividen yang diharapkan & 1 & $1 \%$ \\
\hline $\mathrm{Ne}$ & 21 & Pemberitaan/ulasan di media keuangan & 0 & $0 \%$ \\
\hline $\mathrm{Ne}$ & 22 & Pemberitaan/ulasan di media umum & 0 & $0 \%$ \\
\hline $\mathrm{Ne}$ & 23 & $\begin{array}{l}\text { Perubahan harga dari saham perusahaan baru- } \\
\text { baru ini }\end{array}$ & 0 & $0 \%$ \\
\hline $\mathrm{Ne}$ & 24 & $\begin{array}{l}\text { Ulasan dari analis keuangan yang dipublikasikan } \\
\text { di media }\end{array}$ & 0 & $0 \%$ \\
\hline $\mathrm{Ne}$ & 25 & Kondisi perekonomian saat ini secara umum & 0 & $0 \%$ \\
\hline $\mathrm{Ne}$ & 26 & $\begin{array}{l}\text { Memperhatikan indikator ekonomi (inflasi, } \\
\text { tingkat suku bunga,dll) }\end{array}$ & 0 & $0 \%$ \\
\hline Ac & 27 & Laporan keuangan perusahaan saat ini & 0 & $0 \%$ \\
\hline $\mathrm{Se}$ & 28 & Kemampuan bursa saham saat ini & 0 & $0 \%$ \\
\hline $\mathrm{Se}$ & 29 & Reputasi perusahaan & 0 & $0 \%$ \\
\hline $\mathrm{Se}$ & 30 & Nilai saham perusahaan sebelumnya & 0 & $0 \%$ \\
\hline $\mathrm{Cl}$ & 31 & Harga saham pembukaan & 0 & $0 \%$ \\
\hline $\mathrm{Pe}$ & 32 & $\begin{array}{l}\text { Kinerja portofolio saham yang dimiliki di masa } \\
\text { yang lalu }\end{array}$ & 0 & $0 \%$ \\
\hline $\mathrm{Pe}$ & 33 & $\begin{array}{l}\text { Melakukan perbandingan alternatif investasi } \\
\text { selain saham (obligasi, emas, deposito,dll) }\end{array}$ & 0 & $0 \%$ \\
\hline
\end{tabular}

Sumber: Data Olahan

Keterangan : $\mathrm{Ne} \quad$ : Neutral Information,

Ac : Accounting Information,

Se : Self Image/Firm-Image Coincidence,

$\mathrm{Cl}:$ : Classic,

So : Social Relevance,

Ad : Advocate Recommendation,

$\mathrm{Pe} \quad$ : Personal Financial Need

Untuk analisis masing-masing variabel seperti pada Tabel 5.: untuk urutan pertama dimana semua responden (100\%) menjawab sangat dipertimbangkan dalam keputusan investasi adalah pemberitaan atau ulasan di media keuangan dan kondisi perekonomian saat ini secara umum. Sedangkan laporan keuangan perusahaan saat ini berada pada urutan ke-6 dengan prosentase $97 \%$ dari total keseluruhan, selain itu untuk dividen yang diharapkan hanya 51 (74\%) responden yang menjawab sangat dipertimbangkan. Untuk rekomendasi dari broker berada di urutan ke-26 dengan jumlah 44 (64\%) responden yang menjawab sangat dipertimbangkan.

Berdasarkan hasil analisis tersebut, dapat dilihat faktor yang sangat berpengaruh pada keputuan investasi investor dilihat dari jawaban untuk masing-masing variabel adalah 
Neutral Information dimana informasi-informasi dari luar seperti ulasan dimedia keuangan dan keadaan ekonomi secara umum menjadi penting bagi investor untuk menjadi pertimbangan dalam keputusan investasinya karena jenis informasi ini lebih mudah didapat oleh investor dan ulasan-ulasan biasanya silakukan oleh analis yang terkenal atau pakarnya sehingga investor lebih condong mempertimbangkan faktor ini, kemudian Accounting Information seperti laporan keuangan perusahaan saat ini dan pendapatan perusahaan yang diharapkan masih dipertimbangkan dalam keputusan investasi selain informasi ini mudah diperoleh juga untuk melihat dan menilai kondisi dan profitabilitas perusahaan. Jadi investor sekarang ini tetap memperhatikan faktor Accounting Information dan Neutral Information yang merupakan alat analisis tradisional, hal ini dikarenakan faktor tersebut dianggap mampu mencerminkan tingkat keuntungan yang akan di dapatkan, sehingga motivasi untuk memaksimalkan kekayaan dapat tercapai.

Sedangkan pada Tabel 6. Etika-etika perusahaan, bentuk kepedulian perusahaan terhadap lingkungan (CSR) dan rekomendasi dari broker tidak terlalu dipertimbangkan oleh investor. Hal ini menunjukkan bahwa investor tidak terlalu memperhatikan apakah perusahaan dalam operasi bisnisnya sudah berperilau etis atau belum. Sedangkan untuk CSR adanya kontra dengan program pemerintah yang gencar menganjurkan perusahaan-perusahaan untuk melakukan Corporate Social Responsibility yaitu menyisihkan sebagian laba perusahaan untuk kegiatan sosial bagi masyarakat sekitar perusahaan, namun sebaliknya investor tidak terlalu memperhatikan CSR karena dapat mengurangi dividen yang akan dibagikan pada investor sehingga pemasukannya berkurang. Dan untuk rekomendasi broker juga tidak terlalu diperhatikan karena rekomendasi broker terkadang tidak selalu benar, mereka juga bisa salah dalam memberikan masukan atau pendapatnya sehingga banyak investor yang lebih percaya dengan pendapat atau pemikirannya sendiri. Hanya pendapat broker yang sama atau mendekati dengan analisa investorlah yang akan dipertimbangkan. Dengan demikian investor di Salatiga dan Semarang tidak terlalu memperhatikan behavioral motivation dalam membuat keputusan investasi.

Hal ini berbeda dengan penelitian yang dilakukan oleh Krishnan dan Booker (2002) tentang faktor-faktor yang mempengaruhi keputusan apabila investor yang menggunakan rekomendasi analis untuk sampai pada keputusan jangka pendek untuk menahan atau menjual saham. Hasilnya menunjukkan bahwa rekomendasi analis dalam bentuk laporan ringkas yang sama dengan informasi tambahan yang mendukung, yang digunakan agar mengurangi kesalahan disposisi untuk keuntungan dan juga mengurangi kesalahan disposisi penghapusan. Begitu pula pada penelitian Epstein (1994) meneliti permintaan untuk informasi sosial dengan investor individu. hasil menunjukkan laporan tahunan menjadi bahan pertimbangan yang penting bagi pemegang saham perusahaan. Hasilnya juga menunjukkan permintaan yang kuat untuk informasi tentang keselamatan dan kualitas produk, dan tentang kegiatan lingkungan perusahaan. lebih lanjut, mayoritas pemegang saham perusahaan yang disurvei juga ingin untuk melaporkan etika perusahaan, hubungan karyawan dan keterlibatan masyarakat.

Selain itu hasil penelitian ini juga sejalan dengan penelitian yang dilakukan oleh Al-Tamimi (2004), (Nagy dan Obenberger, 1994) yang dilakukan di Arab dan Amerika menyatakna bahwa adalah faktor yang paling dipertimbangkan investor adalah pendapatan yang dihasilkan perusahaan, kemampuan dari saham perusahaan yang lalu dimana faktor tersebut masuk dalam katagori Neutral information dan Accounting Information. Dengan demikian investor di Salatiga dan Semarang lebih mempertimbangkan faktor economic yang dapat meningkatkan kekayaan investor.

\section{Analisis Crosstab}


Untuk analisis menggunakan tabulasi silang (crosstab) antara aspek demografi (usia, jenis kelamin, pendidikan, dan lama investasi) dengan masing-masing subfaktor hasilnya seperti pada Tabel 6.

Tabel 7. Hasil Analisis Crosstab Usia dengan Kriteria dalam Pengambilan Keputusan Investasi

\begin{tabular}{|c|c|c|c|c|c|c|c|c|}
\hline No & Kriteria & $\begin{array}{l}20- \\
24\end{array}$ & $\begin{array}{l}25- \\
29\end{array}$ & $\begin{array}{l}30- \\
34\end{array}$ & $\begin{array}{l}35- \\
39\end{array}$ & $\begin{array}{l}40- \\
44 \\
\end{array}$ & $\begin{array}{l}45- \\
49\end{array}$ & $\begin{array}{l}50- \\
54 \\
\end{array}$ \\
\hline \multirow{3}{*}{1} & Sangat dipertimbangkan & 99 & 113 & 72 & 52 & 18 & 30 & 12 \\
\hline & Kadang-kadang dipertimbangkan & 3 & 3 & 0 & 2 & 0 & 0 & 0 \\
\hline & $\begin{array}{l}\text { Sama sekali tidak } \\
\text { dipertimbangkan }\end{array}$ & 0 & 0 & 0 & 0 & 0 & 0 & 0 \\
\hline \multirow{3}{*}{2} & Sangat dipertimbangkan & 85 & 106 & 53 & 45 & 17 & 29 & 12 \\
\hline & Kadang-kadang dipertimbangkan & 14 & 18 & 16 & 8 & 1 & 1 & 0 \\
\hline & $\begin{array}{l}\text { Sama sekali tidak } \\
\text { dipertimbangkan }\end{array}$ & 3 & 2 & 3 & 1 & 3 & 0 & 0 \\
\hline \multirow{3}{*}{3} & Sangat dipertimbangkan & 66 & 69 & 42 & 34 & 10 & 25 & 10 \\
\hline & Kadang-kadang dipertimbangkan & 14 & 30 & 12 & 9 & 1 & 0 & 0 \\
\hline & $\begin{array}{l}\text { Sama sekali tidak } \\
\text { dipertimbangkan }\end{array}$ & 5 & 6 & 6 & 2 & 4 & 0 & 0 \\
\hline \multirow{3}{*}{4} & Sangat dipertimbangkan & 59 & 60 & 34 & 27 & 9 & 20 & 8 \\
\hline & Kadang-kadang dipertimbangkan & 5 & 19 & 10 & 8 & 1 & 0 & 0 \\
\hline & $\begin{array}{l}\text { Sama sekali tidak } \\
\text { dipertimbangkan }\end{array}$ & 4 & 5 & 4 & 1 & 2 & 0 & 0 \\
\hline \multirow{3}{*}{5} & Sangat dipertimbangkan & 42 & 52 & 27 & 24 & 7 & 15 & 8 \\
\hline & Kadang-kadang dipertimbangkan & 19 & 26 & 15 & 5 & 2 & 3 & 0 \\
\hline & $\begin{array}{l}\text { Sama sekali tidak } \\
\text { dipertimbangkan }\end{array}$ & 7 & 7 & 6 & 7 & 3 & 2 & 0 \\
\hline \multirow{3}{*}{6} & Sangat dipertimbangkan & 34 & 38 & 20 & 19 & 0 & 10 & 3 \\
\hline & Kadang-kadang dipertimbangkan & 14 & 21 & 13 & 5 & 6 & 5 & 3 \\
\hline & $\begin{array}{l}\text { Sama sekali tidak } \\
\text { dipertimbangkan }\end{array}$ & 4 & 4 & 3 & 3 & 3 & 0 & 0 \\
\hline \multirow{3}{*}{7} & Sangat dipertimbangkan & 75 & 83 & 45 & 35 & 10 & 23 & 10 \\
\hline & Kadang-kadang dipertimbangkan & 11 & 22 & 20 & 7 & 5 & 2 & 0 \\
\hline & $\begin{array}{l}\text { Sama sekali tidak } \\
\text { dipertimbangkan }\end{array}$ & 0 & 0 & 3 & 3 & 0 & 0 & 0 \\
\hline
\end{tabular}

Sumber: Data Olahan

Keterangan : 1 : Neutral Information,

2 : Accounting Information,

3 : Self Image/Firm-Image Coincidence,

4 : Classic,

5 : Social Relevance,

6 : Advocate Recommendation,

7 : Personal Financial Need

Tabel di atas menunjukkan bahwa responden yang berusia $45-54$ tahun menjawab semua variabel sangat dipertimbangkan dalam keputusan investasi hal ini dikarenakan usia 45-54 tahun merupakan usia yang tidak produktif lagi atau mulai pensiun dan usia ini seharusnya masa dimana investor menikmati hasil investasinya dari saat usia produktifnya ,sehingga semua aspek yang berhubungan dengan investasinya mulai diperhatikan semua, kemudian 93,9\% dari usia 25-29 juga mejawab sama untuk usia ini karena investor masih tergolong baru untuk investasi di pasar modal, sebab usia 25-29 mendominasi usia responden yang rata- 
rata lamanya bergabung di Danareksa baru 1-3 tahun saja sehingga semua aspek harus tetap diperhatikan. Sedangkan usia 20-24 tahun menjawab hanya beberapa variabel saja yang sangat dipertimbangkan seperti posisi perusahaan pada industri, dividen yang diharapkan, konsekuensi pajak, rekomendasi dari teman atau teman kerja, dan keinginan diversifikasi hal ini dikarenakan pada usia ini selain belum berpengalaman juga masih emosional dan terburu-buru sehingga hanya mempertimbangkan beberapa variabel saja. Dan untuk usia matang responden yaitu usia 30-44 tahun hampir semua tidak banyak mempertimbangkan variabel-variabel keputusan investasi dalam kegiatan investasinya karena pada usia ini pengalaman sudah banyak dan emosi mulai terkendali sehingga dalam keputusan investasinya lebih pada logika sehingga variabel yang sesuai dengan logikanya saja yang diperhatikan.

Tabel 8. Hasil Analisis Crosstab Jenis Kelamin dengan Kriteria dalam Pengambilan Keputusan Investasi

\begin{tabular}{|c|l|c|c|}
\hline No. & \multicolumn{1}{|c|}{ Kriteria } & Laki-laki & Perempuan \\
\hline \multirow{4}{*}{1} & Sangat dipertimbangkan & 346 & 60 \\
\cline { 2 - 4 } & Kadang-kadang dipertimbangkan & 8 & 0 \\
\cline { 2 - 4 } & Sama sekali tidak dipertimbangkan & 0 & 0 \\
\hline \multirow{4}{*}{2} & Sangat dipertimbangkan & 289 & 55 \\
\cline { 2 - 4 } & Kadang-kadang dipertimbangkan & 53 & 5 \\
\cline { 2 - 4 } & Sama sekali tidak dipertimbangkan & 12 & 0 \\
\hline \multirow{4}{*}{3} & Sangat dipertimbangkan & 211 & 45 \\
\cline { 2 - 4 } & Kadang-kadang dipertimbangkan & 61 & 5 \\
\cline { 2 - 4 } & Sama sekali tidak dipertimbangkan & 23 & 0 \\
\hline \multirow{4}{*}{4} & Sangat dipertimbangkan & 180 & 37 \\
\cline { 2 - 4 } & Kadang-kadang dipertimbangkan & 42 & 3 \\
\cline { 2 - 4 } & Sama sekali tidak dipertimbangkan & 16 & 0 \\
\hline \multirow{3}{*}{5} & Sangat dipertimbangkan & 147 & 28 \\
\cline { 2 - 4 } & Kadang-kadang dipertimbangkan & 60 & 10 \\
\cline { 2 - 4 } & Sama sekali tidak dipertimbangkan & 29 & 2 \\
\hline \multirow{3}{*}{6} & Sangat dipertimbangkan & 101 & 23 \\
\cline { 2 - 4 } & Kadang-kadang dipertimbangkan & 59 & 7 \\
\cline { 2 - 4 } & Sama sekali tidak dipertimbangkan & 17 & 0 \\
\hline \multirow{4}{*}{7} & Sangat dipertimbangkan & 235 & 44 \\
\cline { 2 - 4 } & Kadang-kadang dipertimbangkan & 54 & 6 \\
\cline { 2 - 4 } & Sama sekali tidak dipertimbangkan & 6 & 0 \\
\hline \multirow{2}{*}{$54 m b$} & Da Data Olahan & & \\
\hline
\end{tabular}

Sumber: Data Olahan

Keterangan : 1 : Neutral Information,

2 : Accounting Information,

3 : Self Image/Firm-Image Coincidence,

4 : Classic,

5 : Social Relevance,

6 : Advocate Recommendation,

7 : Personal Financial Need

Kemudian untuk analisis keputusan investasi berdasarkan jenis kelamin yaitu perempuan lebih berhati-hati dalam keputusan investasinya dilihat dari hasil analisis yang menunjukkan bahwa sebagian besar responden berjenis kelamin perempuan sangat memperhatikan semua variabel yang berhubungan dengan keputusan investasi bila dibandingkan dengan 
laki-laki. Hal ini dapat didukung dengan pengklasifikasian karakteristik ekspresif (Bason dalam Setiawati, 2009), karena perempuan tidak terlalu mandiri, sangat emosional, sangat tidak logis, sulit membuat keputusan, tidak terlalu percaya diri, dan sangat membutuhkan rasa aman. Sedangkan banyak responden laki-laki yang tidak banyak mempertimbangkan variabel-variabel yang ada yang berhubungan dengan keputusan investasinya, karena karekter laki-laki berbanding terbalik dengan perempuan yaitu sangat mandiri, tidak terlalu emosional, sangat logis, mudah membuat keputusan, sangat percaya diri, dan tidak terlalu membutuhkan rasa aman.

\section{Tabel 9. Hasil Analisis Crosstab Tingkat Pendidikan dengan Kriteria dalam Pengambilan Keputusan Investasi}

\begin{tabular}{|c|l|c|c|c|}
\hline No. & \multicolumn{1}{|c|}{ Kriteria } & SMA & S1 & S2 \\
\hline \multirow{4}{*}{1} & Sangat dipertimbangkan & 99 & 113 & 72 \\
\cline { 2 - 5 } & Kadang-kadang dipertimbangkan & 3 & 3 & 0 \\
\cline { 2 - 5 } & Sama sekali tidak dipertimbangkan & 0 & 0 & 0 \\
\hline \multirow{4}{*}{2} & Sangat dipertimbangkan & 85 & 106 & 53 \\
\cline { 2 - 5 } & Kadang-kadang dipertimbangkan & 14 & 18 & 16 \\
\cline { 2 - 5 } & Sama sekali tidak dipertimbangkan & 3 & 2 & 3 \\
\hline \multirow{4}{*}{3} & Sangat dipertimbangkan & 66 & 69 & 42 \\
\cline { 2 - 5 } & Kadang-kadang dipertimbangkan & 14 & 30 & 12 \\
\cline { 2 - 5 } & Sama sekali tidak dipertimbangkan & 5 & 6 & 6 \\
\hline \multirow{4}{*}{5} & Sangat dipertimbangkan & 59 & 60 & 34 \\
\cline { 2 - 5 } & Kadang-kadang dipertimbangkan & 5 & 19 & 10 \\
\cline { 2 - 5 } & Sama sekali tidak dipertimbangkan & 4 & 5 & 4 \\
\hline \multirow{4}{*}{5} & Sangat dipertimbangkan & 42 & 52 & 27 \\
\cline { 2 - 5 } & Kadang-kadang dipertimbangkan & 19 & 26 & 15 \\
\cline { 2 - 5 } & Sama sekali tidak dipertimbangkan & 7 & 7 & 6 \\
\hline \multirow{3}{*}{6} & Sangat dipertimbangkan & 34 & 38 & 20 \\
\cline { 2 - 5 } & Kadang-kadang dipertimbangkan & 14 & 21 & 13 \\
\cline { 2 - 5 } & Sama sekali tidak dipertimbangkan & 4 & 4 & 3 \\
\hline \multirow{4}{*}{7} & Sangat dipertimbangkan & 75 & 83 & 45 \\
\cline { 2 - 5 } & Kadang-kadang dipertimbangkan & 11 & 22 & 20 \\
\cline { 2 - 5 } & Sama sekali tidak dipertimbangkan & 0 & 0 & 3 \\
\hline \multirow{2}{*yyyy}{} & Ser Data Olahan & & & \\
\hline
\end{tabular}

Sumber: Data Olahan

Keterangan : 1 : Neutral Information,

2 : Accounting Information,

3 : Self Image/Firm-Image Coincidence,

4 : Classic,

5 : Social Relevance,

6 : Advocate Recommendation,

7 : Personal Financial Need

Dari tabel diatas dapat dilihat bahwa sebagian besar responden adalah lulusan S1, dimana tingkat pendidikan tersebut tergolong tinggi sehingga pengetahuan dalam menganalisa sesuatu dapat dikatakan sudah cukup bagus, namun ternyata investor tersebut masih belum dapat memproritaskan faktor-faktor yang memang dibutuhkan dalam keputusan investasinya.

Tabel 10. Hasil Analisis Crosstab Lama Investasi dengan Kriteria dalam Pengambilan Keputusan Investasi 


\begin{tabular}{|c|l|c|c|c|c|}
\hline No. & \multicolumn{1}{|c|}{ Kriteria } & $<1$ & $1-3$ & $4-6$ & $>6$ \\
\hline \multirow{4}{*}{1} & Sangat dipertimbangkan & 6 & 270 & 76 & 54 \\
\cline { 2 - 6 } & Kadang-kadang dipertimbangkan & 0 & 6 & 2 & 0 \\
\cline { 2 - 6 } & Sama sekali tidak dipertimbangkan & 2 & 247 & 48 & 47 \\
\hline \multirow{4}{*}{2} & Sangat dipertimbangkan & 4 & 24 & 26 & 4 \\
\cline { 2 - 6 } & Kadang-kadang dipertimbangkan & 0 & 5 & 4 & 3 \\
\cline { 2 - 6 } & Sama sekali tidak dipertimbangkan & 2 & 185 & 32 & 46 \\
\hline \multirow{4}{*}{3} & Sangat dipertimbangkan & 3 & 36 & 25 & 2 \\
\cline { 2 - 6 } & Kadang-kadang dipertimbangkan & 0 & 9 & 8 & 6 \\
\cline { 2 - 6 } & Sama sekali tidak dipertimbangkan & 4 & 155 & 27 & 31 \\
\hline \multirow{4}{*}{5} & Sangat dipertimbangkan & 0 & 21 & 20 & 2 \\
\cline { 2 - 6 } & Kadang-kadang dipertimbangkan & 0 & 8 & 5 & 3 \\
\cline { 2 - 6 } & Sama sekali tidak dipertimbangkan & 1 & 137 & 13 & 24 \\
\hline \multirow{4}{*}{5} & Sangat dipertimbangkan & 3 & 34 & 24 & 9 \\
\cline { 2 - 6 } & Kadang-kadang dipertimbangkan & 0 & 13 & 15 & 3 \\
\cline { 2 - 6 } & Sama sekali tidak dipertimbangkan & 0 & 104 & 11 & 9 \\
\hline \multirow{4}{*}{6} & Sangat dipertimbangkan & 3 & 27 & 21 & 15 \\
\cline { 2 - 6 } & Kadang-kadang dipertimbangkan & 0 & 7 & 7 & 3 \\
\cline { 2 - 6 } & Sama sekali tidak dipertimbangkan & 0 & 201 & 40 & 38 \\
\hline \multirow{4}{*}{7} & Sangat dipertimbangkan & 5 & 29 & 19 & 7 \\
\cline { 2 - 6 } & Kadang-kadang dipertimbangkan & 0 & 0 & 6 & 0 \\
\cline { 2 - 6 } & Sama sekali tidak dipertimbangkan & 0 & 0 & 3 & 0 \\
\hline \multirow{2}{*yyyyy}{} & Data Olahan & & & & \\
\hline
\end{tabular}

Sumber: Data Olahan

Keterangan : 1 : Neutral Information,

2 : Accounting Information,

3 : Self Image/Firm-Image Coincidence,

4 : Classic,

5 : Social Relevance,

6 : Advocate Recommendation,

7 : Personal Financial Need

Lamanya investasi juga mempengaruhi keputusan investasi investor, bagi investor yang masih baru dalam berinvestasi sangat mempertimbangkan semua faktor yang berhubungan dengan keputusan investasinya. Sedangkan semakin lama seorang investor melakukan investasi maka semakin berkurang atau semakin sedikit faktor yang dipertimbangkan sebab semakin lama semakin banyak pengalaman sehingga keputusan investasi lebih banyak berdasarkan pengalamannya saja.

\section{KESIMPULAN DAN SARAN}

Berdasarkan hasil analisis yang telah diuraikan dalam penelitian ini, dapat disimpulkan bahwa faktor yang banyak dipertimbangkan investor dalam melakukan investasi adalah Neutral Information, Accounting Information, dan aspek demografi juga mempengaruhi keputusan investasi investor.

Sedangkan untuk variabel demografi dapat disimpulkan bahwa investor yang berusia muda 25-29 dan tua 50-54 yang mempertimbangkan hampir semua faktor, sedangkan usia dibawah dan diatas 25-29 tidak terlalu banyak mempertimbangkan banyak faktor. Sedangkan jika dilihat dari jenis kelamin, investor perempuan masih terlalu takut sehingga 
sangat berhatu-hati dalam mengambil keputusan karena semua faktor sangat dipertimbangkan dalam keputusan investasinya. Tingkat pendidikan juga mempengaruhi keputusan investasi seseorang, dengan tingkat pendidikan yang sudah tergolong tinggi tidak membuat investor percaya diri untuk menentukan faktor-faktor mana yang lebih penting, investor lulusan Sipun masih mempertimbangkan semua faktor yang berhubungan dengan kegiatan investasinya. Disamping ketiga aspek diatas, lamanya investor dalam berinvestasi juga berpengaruh dalam menentukan faktor yang harus dipertimbangkan. Investor yang terolong masih barulah yaitu 1-3 tahun yang masih memperhatikan dan mempertimbangkan semua faktor sebelum mengambil keputusan, sedangkan investor yang sudah cukup lama berinvestasi sudah mulai mengurangi faktor-faktor yang harus dipertimbangkan dalam keputusan investasinya.

Jadi hasil penelitian ini sejalan dengan penelitian-penelitian sebelumnya yang dilakukan di negara lain. Investor di Indonesia dalam melakukan investasi berdasarkan Economic Factor.

Kelemahan dari penelitian ini baru melihat faktor-faktor yang diperimbangkan investor, namun belum melilhat apakah terjadi pengaruh anatara faktor-faktor yang dipertimbangkan dengan permintaan dari saham perusahaan.

Saran untuk penelitian mendatang sebaiknya perlu dilakukan penambahan variabel religius untuk keputusan investasi di perusahaan yang berbasis syariah, sebab perusahaan berasis syariah sekarang ini mulai berkembang dan di minati oleh banyak investor. Selain itu juga melakukan analisis regresi antara faktor yang dipertimbangkan dengan permintaan saham.

\section{DAFTAR PUSTAKA}

Al-Tamimi Hussein A. Hassan, 2004, "Factors Influencing Individual Investor Behavior: An Empirical study of the UAE Financial Markets," Associate Professor Department of Business Administration College of Business and Management. United Arab Emirates: University of Sharjah, pp. 1-24

Halim Abdul, 2005, Analisis Investasi, Edisi 2, Salemba empat, Jakarta

Khairani Rahma dan Putri Dona Eka, 2009, "Perbedaan Kematangan Emosi Pada Pria dan Wanita yang Menikah Muda", Proceeding PESAT (Psikologi, Ekonomi, Sastra, Arsitektur, \& Sipil) Vol 3, Depok: Universitas Gunadarma, pp. A1-A6

Kumar Alok, 2009, "Dynamic Style Preferences of Individual Investors and Stock Return,", Journal of Financial \& Quantitative Analysis

M. E. Blume dan Irwin Friend, 1978, "The Changing Role of the Individual Investor", (New York: John Wiley and Sons

Nagy Robert A. dan Obenberger Robert W, 1994, "Factors Influencing Individual Investor Behavior," Financial Analysts Journal, pp. 63-68

Ritter Jay. R, "Behavioral Finance," Pacific-Basin Finance Journal Vol. 11, No 4, (September 2003), pp. 429-437

See J. Von Neumann dan O. Morgenstern, 1947, "Theory of Games and Economic Behavior ", Princeton: Princeton University Press

Setiawati Devi. 2009. "Perbedaan Komitmen Kerja Berdasarkan Orientasi Peran Gender", Depok: Universitas Gunadarma.

Toral Al, 2002, 'Other Ways to Score Invesment Points", Pure Fundamentalist

Waskito Jati dan Irmawati. H., 2007, "Perbedaan Gender dan Sikap Terhadap Peran Pekerjaan-Keluarga: Implikasinya Pada Perkembangan Karir Wanita", BENEFIT Jurnal Manajemen dan Bisnis Vol. 11, No 1, pp. 87-95 
W. E. Warren, R. E. Stevens dan C. W. McConkey, 1990, "Using Demographic and Lifestyle Analysis to Segment Individual Investor," Financial Analysts Journal

W. G. Lewellen, R. C. Lease dan G. C. Schlarbaum, 1977, "Patterns Of Investment Strategy And Behavior Among Individual Investor", Journal Of Business, pp. 296-333 